\title{
First Dual-Band Multiconstellation GNSS-R Scatterometry Experiment Over Boreal Forests From a Stratospheric Balloon
}

\author{
Hugo Carreno-Luengo, Member, IEEE, and Adriano Camps, Fellow, IEEE
}

\begin{abstract}
This work presents the first ever dual-frequency multiconstellation Reflectometry using Global Navigation Satellite Systems signals (GNSS-R) observations over boreal forests and lakes using GPS, GLONASS, and Galileo signals. The instrument used is the PYCARO reflectometer, which flew on-board a stratospheric balloon during the SNSB and ESA sponsored BEXUS 19 experiment. The coherent-to-incoherent scattering ratio over boreal forests is found to be as large as $\sim 1.5$, while over lakes, it is as high as 16.5. The scatterers' height fluctuations measured using the phase of the peak of the reflected complex waveforms ranges from $\pm 10 \mathrm{~m}$, to the submetric level. Finally, reflectivity maps using the different GNSS codes are presented using the conventional GNSS-R for the open-access codes, and the reconstructed GNSS-R for the encrypted ones. The coherence of the reflected signal is found to be high enough to allow the PYCARO instrument to reconstruct the $P(Y)$ code.
\end{abstract}

Index Terms-Biomass monitoring, boreal forests, Reflectometry using Global Navigation Satellite Systems signals (GNSS-R), rGNSS-R, scatterometry, stratospheric balloon.

\section{INTRODUCTION}

$\mathbf{R}$ EFLECTOMETRY using Global Navigation Satellite Systems signals (GNSS-R) is a promising new remote sensing technique. It was originally proposed to improve the temporal resolution of classical space-borne ocean nadirlooking altimeters so as to detect mesoscale signatures [1]. Wind speed measurements [2], ice altimetry [3], soil moisture, and vegetation determination [4] can also be inferred using GNSS-R. Several experiments have been carried out in the last years to analyze the performance of different GNSS-R techniques: conventional GNSS-R or cGNSS-R (GPS L1 CA) (e.g., [5]), interferometric GNSS-R or iGNSS-R (GPS L1 CA, $\mathrm{P}(\mathrm{Y})$, and $\mathrm{M})[6]$, and reconstructed-code GNSS-R or rGNSSR (GPS L1\&L2 P(Y)) [7]. More recently, two ground-based

Manuscript received June 04, 2015; revised September 10, 2015; accepted October 26, 2015. Date of publication November 24, 2015; date of current version October 14, 2016. This work was supported in part by European Union's Seventh Framework Programme for research, technological development, and demonstration under Grant agreement "European GNSS-R Environmental Monitoring" no. FP7-607126-E-GEM (Online Available: http://www.e-gem. eu), and in part by the project "Aplicaciones avanzadas en radio ocultaciones y dispersometría utilizando señales GNSS y otras señales de oportunidad" of the Spanish Ministerio de Ciencia e Innovación (MICINN) under Grant AYA2011-29183-C02-01.

The authors are with the Universitat Politèctica de Catalunya (UPC), BarcelonaTech Remote Sensing Laboratory and the Institut d'Estudis Espacials de Catalunya, Barcelona 08034, Spain (e-mail: carrenyo@ieec.cat).

Color versions of one or more of the figures in this paper are available online at http://ieeexplore.ieee.org.

Digital Object Identifier 10.1109/JSTARS.2015.2496661 low-altitude experiments using the Galileo E1/E5a/E5b signals [8], and the GLONASS L1 composite signal [9] have been performed over a lake and from a pier over the North Sea, respectively.

Boreal forests cover $\sim 15 \%$ of Earth's land surface. Mapping boreal biomass is a key factor to study the carbon cycle. European Space Agency ESA's BIOMASS mission for example will focus in this variable using a P-band SAR (e.g., [10]). Some studies have shown the potential of GNSS-R to measure forest biomass [11]. At present, United Kingdom UK TechDemoSat-1 [12], National Aeronautics and Space Administration NASA's CyGNSS mission [13], European Space Agency ESA's GNSS rEflectometry, Radio Occultation and Scatterometry experiment on-board the International Space Station (GEROS-ISS) [14], ESA's Passive Reflectometry and Interferometry System In-Orbit Demonstrator (PARIS-IoD) [15], and ${ }^{3}$ Cat-2 6U CubeSat [16] include GNSS-R payloads.

A scattering model considering both the coherent and incoherent scattered fields was proposed in [11]. This model predicts the coherent field as the result of the electromagnetic interactions of the GNSS signals with the soil only, attenuated by the vegetation canopy above it. In [17], experimental data over forest biomass from 100 to 350 t/ha using GPS signals was reported. As predicted in [11], a lower value of the coherent soil-reflectivity is found for larger vegetation density. The coherent scattering over a rough soil including antenna pattern effects was studied in [18], and applied later to the GNSS-R case for vegetation-covered soils [19]. More recently, a different approach has been proposed that states that the forward scattering coefficient is governed by the scattering properties of the vegetation elements and the soil surface, as well as by the interaction between the canopy and the soil, and the soil with the trunks [20].

In 1999, the first GNSS-R stratospheric balloon experiment was performed over sea surface [21]. This work presents the first GNSS-R dual-frequency (L1 and L2), multiconstellation (GPS and GLONASS, and for E1 Galileo) observations over boreal forests, from a stratospheric balloon using the $\mathrm{P}(\mathrm{Y})$ and C/A ReflectOmeter (PYCARO) in closed-loop mode. The study is performed using data from the float phase of the flight $(h \sim 27,000 \mathrm{~m})$ and with GNSS satellites at a high elevation angle in the range $\theta_{e}=\left[45^{\circ}, 70^{\circ}\right]$. Section II describes the setup used in this experiment carried out North of Sweden on October 8, 2014 on-board the Swedish National Space Board (SNSB) and ESA sponsored 


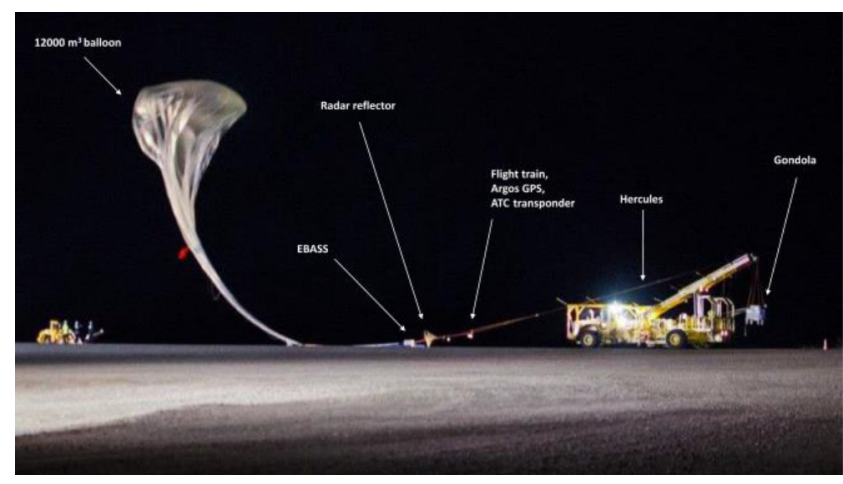

Fig. 1. BEXUS 19 stratospheric balloon during take-off at Esrange Space Center. Typical BEXUS configuration: $12,000 \mathrm{~m}^{3}$ balloon, valve, cutter, parachute, Esrange Balloon Service System (EBASS), flight train, Argos GPS, and Air Traffic Control (ATC) transponder (AGT), strobe light, radar reflector, and gondola. Total length of the system is up to $75 \mathrm{~m}$ [24]. Photo Credits: SNSB-K. Dannenberg.

Balloon EXperiments for University Students (BEXUS) 19 stratospheric balloon. Section III describes the theoretical framework. Section IV describes the experimental results. Finally, Section V summarizes the main results of this study.

\section{EXPERIMENTAL SETUP}

The BEXUS programme is implemented under a bilateral agency agreement between the German Aerospace Center (DLR) and the SNSB. The BEXUS 19 stratospheric balloon (Fig. 1) launch campaign took place in Esrange Space Center from October 3 to 13, 2014. The launch took place on October 8, 2014 at $18 \mathrm{~h}$ (GPS Time), and the flight duration was $4 \mathrm{~h}$ with an apogee of $\sim 27,000 \mathrm{~m}$. The trajectory was a single track from Esrange Space Center (latitude $67^{\circ} 53^{\prime} \mathrm{N}$, longitude $21^{\circ} 04^{\prime} \mathrm{E}$ ) to the Finland Lapland (latitude $68^{\circ} 04^{\prime} \mathrm{N}$, longitude $25^{\circ} 81^{\prime} \mathrm{E}$ ) over boreal forests with a density $\sim 100 \mathrm{t} / \mathrm{ha}$, and a tree height of $\sim 20 \mathrm{~m}$ [22], [23].

The experimental setup was composed of the PYCARO rGNSS-R instrument [7], both a dual-band (L1, L2) and dualpolarization ${ }^{1}$ (right- and left-hand circular polarization: RHCP, LHCP) zenith-looking patch antenna to collect the direct GNSS signals, and a nadir-looking antenna array to collect the Earthreflected signals (Fig. 2), an On-Board Computer (OBC) for the experiment management, and an active thermal control, since the outside temperature went down to $-70^{\circ} \mathrm{C}$. The nadir-looking antenna was composed of six elementary antenna patches (Fig. 2). The total gain of the antenna was $12.9 \mathrm{~dB}$ at L1-LHCP, $13.3 \mathrm{~dB}$ at L1-RHCP, $11.6 \mathrm{~dB}$ at L2-LHCP, and $11.6 \mathrm{~dB}$ al L2-RHCP. The On-Board Data Handling (OBDH) subsystem was composed of a Commercial Off-The-Shelf (COTS) microcontroller for housekeeping and scientific data management, communications with the ground station, and data storage in a micro-SD. The collected data were registered in two internal SD memories (PYCARO and microcontroller), and they were simultaneously sent to the ground segment via the E-Link system [24].

\footnotetext{
${ }^{1}$ In this study, only left-hand circular polarization (LHCP) reflected signals are evaluated.
}

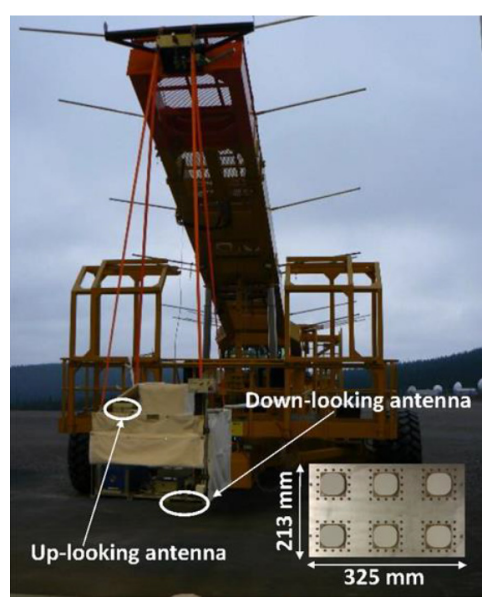

Fig. 2. Up-looking and down-looking antenna array inside the thermally insulating radomes on-board the BEXUS 19 gondola.

\section{TheOreticAl Framework}

The GNSS-reflectometer used is the PYCARO instrument operated in closed-loop mode with delay and phase tracking loops activated that uses the cGNSS-R technique for the open-access codes, and the rGNSS-R one for the encrypted codes. The complex cross-correlation waveform of the direct signal is proportional to the electromagnetic field reaching the instrument as [25]

$$
\begin{aligned}
& Y_{d}\left(\tau, f_{c}\right) \propto T_{c} \cdot W A F\left(\tau, f_{c}\right) \\
& \quad \approx T_{c} \cdot A C F(\tau) \frac{\sin \left(\pi f_{c} T_{c}\right)}{\pi f_{c} T_{c}} e^{-j \pi f_{c} T_{c}}
\end{aligned}
$$

where $\tau$ is the delay of the signal from the transmitter to the receiver, $f_{c}$ is the carrier frequency of the direct electromagnetic signal, $T_{c}$ is the coherent integration time, $W A F$ is the well-known Woodward ambiguity function, $A C F(\tau)$ is the autocorrelation function of the code, and $j=\sqrt{-1}$ is the imaginary unit.

The complex waveform associated to the field scattered by an ensemble of scatterers such as soil, and trunks, branches, and leaves of a forest will consist of the sum of a finite number of WAFs each one affected by a complex weight $\left(a_{m}=\left|a_{m}\right| e^{j \phi_{m}}\right)$ that accounts for the scattering amplitude of the electromagnetic field, delayed by a delay $\delta \tau_{m}$ and affected by a Doppler shift $\delta f_{m}$

$$
\begin{gathered}
Y_{r}\left(\tau, f_{c, s p}\right)=T_{c} \sum_{m=1}^{M}\left|a_{m}\right| e^{j \phi_{m}} \\
W A F\left(\tau+\delta \tau_{m}, f_{c, s p}+\delta f_{m}\right) \approx T_{c} \sum_{m=1}^{M}\left|a_{m}\right| e^{j \phi_{m}} \\
A C F\left(\tau+\delta \tau_{m}\right) \frac{\sin \left(\pi\left(f_{c, s p}+\delta f_{m}\right) T_{c}\right)}{\pi\left(f_{c, s p}+\delta f_{m}\right) T_{c}} e^{-j \pi\left(f_{c, s p}+\delta f_{m}\right) T_{c}}
\end{gathered}
$$

where $f_{c, s p}$ is the Doppler shift of the electromagnetic signal reflected at the nominal specular point. Actually, (2) can be understood as the discrete version of the integrated form in [26]. 
TABLE I

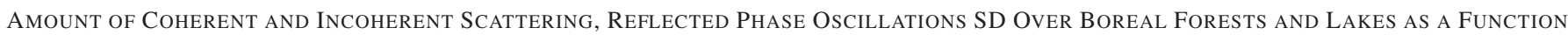
of the Elevation ANGLe For: GPS, GLONASS, AND Galileo Signals at a Flight Height of $h \sim 27,000 \mathrm{~m}$

\begin{tabular}{|c|c|c|c|c|}
\hline & $\begin{array}{c}\text { L1 C/A } \\
\text { FORESTS } \\
\end{array}$ & $\begin{array}{c}\text { L2 C } \\
\text { FORESTS } \\
\end{array}$ & $\begin{array}{l}\text { L1 C/A } \\
\text { LAKES }\end{array}$ & $\begin{array}{c}\text { L2 C } \\
\text { LAKES }\end{array}$ \\
\hline \multicolumn{5}{|l|}{ GPS, $h \approx 27,000 \mathrm{~m}, \theta_{e}=\left[45^{\circ}, 70^{\circ}\right]$} \\
\hline Coherent scattering: $\quad\left|\left\langle Y_{r, \text { Peak }}\right\rangle\right|^{2}$ (A.U.) & 33,782 & 6037 & 199,090 & 33,015 \\
\hline Incoherent scattering: $\sigma_{\text {Real }\left(Y_{r}, \text { Peak }\right)}^{2}+\sigma_{I m\left(Y_{r}, \text { Peak }\right)}^{2}$ (A.U.) & $16,888+4178$ & $3102+622$ & $32,569+15,363$ & $2910+1238$ \\
\hline Ratio $B^{2}$ & 1.6 & 1.6 & 4.1 & 7.9 \\
\hline \multirow[t]{3}{*}{ Reflected phase oscillations std. (degrees) } & 30 & 27 & 20.7 & 12.5 \\
\hline & L1 C/A & L2 C/A & L1 C/A & $\mathrm{L} 2 \mathrm{C} / \mathrm{A}$ \\
\hline & FORESTS & FORESTS & LAKES & LAKES \\
\hline GLONASS, $h \approx 27,000 \mathrm{~m}, \theta_{e}=\left[45^{\circ}, 70^{\circ}\right]$ & N.A. & & N.A. & \\
\hline \multirow{2}{*}{$\begin{array}{c}\text { Coherent scattering: } \quad\left|\left\langle Y_{r, \text { Peak }}\right\rangle\right|^{2} \text { (A.U.) } \\
\text { Incoherent scattering: } \quad \sigma_{\text {Real }\left(Y_{r}, P_{\text {eak }}\right)}^{2}+\sigma_{I m\left(Y_{r}, \text { Peak }\right)}^{2} \text { (A.U.) }\end{array}$} & $\mathrm{x}$ & 9761 & $\mathrm{x}$ & 32,508 \\
\hline & $\mathrm{x}$ & $4610+1686$ & $\mathrm{x}$ & $5847+2439$ \\
\hline \multirow{4}{*}{$\begin{array}{c}\text { Ratio } B^{2} \\
\text { Reflected phase oscillations std. (degrees) } \\
\end{array}$} & $\mathrm{x}$ & 1.5 & $\mathrm{x}$ & 3.9 \\
\hline & $\mathrm{x}$ & 35 & $\mathrm{x}$ & 19.8 \\
\hline & $\mathrm{E} 1 \mathrm{BC}$ & & $\mathrm{E} 1 \mathrm{BC}$ & \\
\hline & FORESTS & & LAKES & \\
\hline \multicolumn{2}{|l|}{ Galileo, $h \approx 27,000 \mathrm{~m}, \theta_{e}=\left[60^{\circ}, 70^{\circ}\right]$} & N.A. & & N.A. \\
\hline \multirow{4}{*}{$\begin{array}{c}\text { Coherent scattering: }\left|\left\langle Y_{r, \text { Peak }}\right\rangle\right|^{2} \text { (A.U.) } \\
\text { Incoherent scattering: } \quad \sigma_{\text {Real }\left(Y_{r}, \text { Peak }\right)}^{2}+\sigma_{I m\left(Y_{r}, \text { Peak }\right)}^{2} \text { (A.U.) } \\
\text { Ratio } B^{2} \\
\text { Reflected phase oscillations std. (degrees) }\end{array}$} & 3434 & $\mathrm{x}$ & 68,069 & $\mathrm{x}$ \\
\hline & $1208+423$ & $\mathrm{x}$ & $3477+658$ & $\mathrm{x}$ \\
\hline & 2.1 & $\mathrm{x}$ & 16.5 & $\mathrm{x}$ \\
\hline & 28.2 & $\mathrm{x}$ & 5.7 & $\mathrm{x}$ \\
\hline
\end{tabular}

A detailed analysis of the cross-correlation properties $(A C F)$ of different navigation signals is provided in [27].

The phase difference before retracking $\left(\delta \Psi_{n}\right)$ between the peak amplitude of the direct and the reflected complex waveforms at time $t_{n}$ is used to infer the geometric delay $\rho_{g e o, n}$ as

$$
\rho_{g e o, n}=\frac{\lambda \delta \Psi_{n}}{2 \pi}
$$

where $\lambda$ is the signal wavelength. Height ${ }^{2}$ changes $\delta h_{n}$ of the center of phase of the scatterers (soil, trunks, branches, and leaves) that contribute to the peak of the amplitude of the complex reflected waveform $Y_{r, \text { Peak }}\left(\tau_{\text {Peak }}, f_{c, \text { Peak }}\right)$ are related to the difference of the geometric delays $\delta \rho_{g e o, n}$ between two consecutive samples as [28]

$$
\delta h_{n}=\frac{\delta \rho_{g e o, n}}{2 \sin \theta_{e}}=\frac{\rho_{g e o, n}-\rho_{g e o, n-1}}{2 \sin \theta_{e}}
$$

where $\theta_{e}$ is the elevation angle. Finally, since we are using differential measurements with a period defined by the coherent integration time of the waveforms $\left(T_{c}\right)$, the phase delays introduced by the atmosphere are implicitly cancelled out because they can be assumed to be constant during these short periods of time.

GPS satellites' motion and receiver's motion as well induce a change in the delay, and the phase difference of the waveforms.

\footnotetext{
${ }^{2}$ Precise flight trajectory provided by Swedish Space Corporation (SSC) computed using a GPS receiver on-board the balloon, and small platform height variations were compensated for. Vertical speed of the balloon during the float phase was smaller than $1 \mathrm{~m} / \mathrm{s}$, which prevented phase jumps.
}

TABLE II

Optimum Delay and Phase Locked Loop Parameters USED DURING the FloAt PHASE OF THE EXPERIMENT FOR GPS [29],

\begin{tabular}{|c|c|c|c|c|c|}
\hline GNSS code & $\begin{array}{l}T_{c}^{P L L} \\
(\mathrm{~ms})\end{array}$ & $\begin{array}{c}B^{P L L} \\
(\mathrm{~Hz})\end{array}$ & $\begin{array}{l}T_{c}^{D L L} \\
(\mathrm{~ms})\end{array}$ & $\begin{array}{c}N_{i n c}^{D L L} \\
\text { (complex } \\
\text { waveforms ) }\end{array}$ & $\begin{array}{c}B^{D L L} \\
(\mathrm{~Hz})\end{array}$ \\
\hline GPS L1 C/A & 10 & 15 & 20 & 1 & 0.01 \\
\hline GPS L2 C [29] & 10 & 15 & 20 & 1 & 0.01 \\
\hline GPS L2 P(Y) & 10 & 15 & 20 & 1 & 0.01 \\
\hline GPS L1 P(Y) & 10 & 15 & 20 & 1 & 0.01 \\
\hline $\begin{array}{l}\text { GLONASS L1 } \\
\text { C/A [31] }\end{array}$ & 10 & 15 & 10 & 2 & 0.01 \\
\hline $\begin{array}{c}\text { GLONASS L2 } \\
\text { C/A [31] }\end{array}$ & 10 & 15 & 10 & 2 & 0.01 \\
\hline $\begin{array}{c}\text { GLONASS L2 P } \\
{[30]} \\
\end{array}$ & 4 & 15 & 4 & 5 & 0.01 \\
\hline $\begin{array}{c}\text { Galileo E1 BC } \\
{[32]}\end{array}$ & 4 & 15 & 4 & 5 & 0.01 \\
\hline
\end{tabular}
GLONASS [30], [31], AND GALILEO SigNALS [32]

The PYCARO reflectometer compensates these changes to perform the coherent and incoherent averaging. In addition to the phase of the peak of the reflected waveforms before retracking $Y_{r}\left(\tau_{\text {Peak }}, f_{c, \text { Peak }}\right)$, one important scientific observable is the phase $\Omega_{n}$ of the peak of the complex reflected waveforms after being retracked, to center the tracking delay and Doppler windows. 


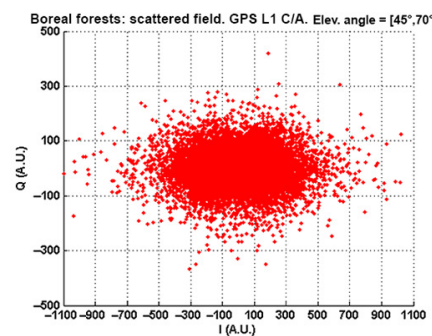

(a)

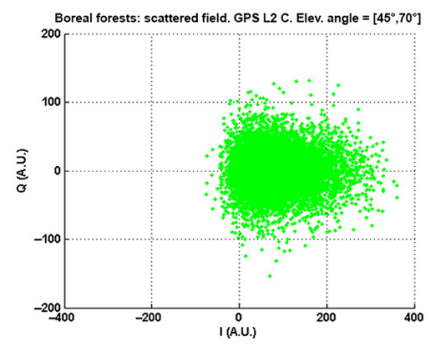

(c)

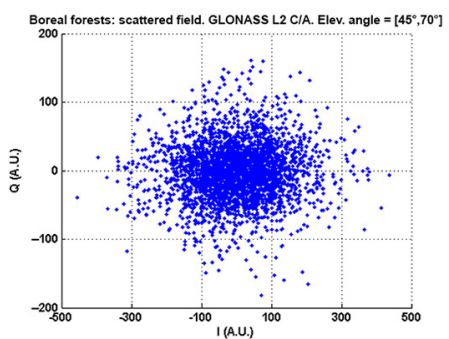

(e)

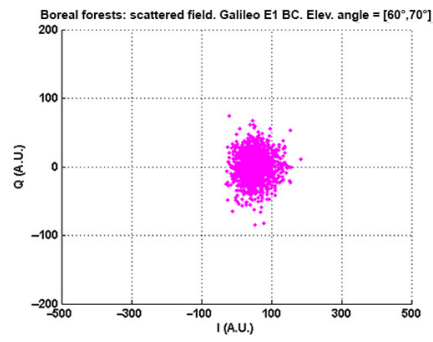

(g)

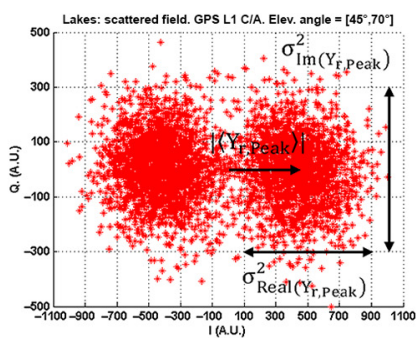

(b)

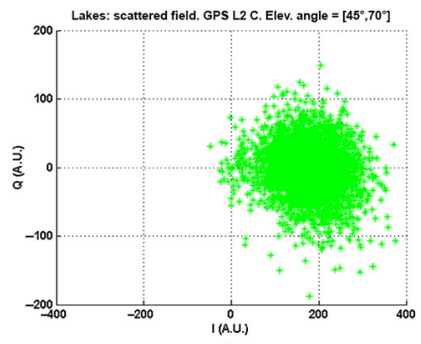

(d)

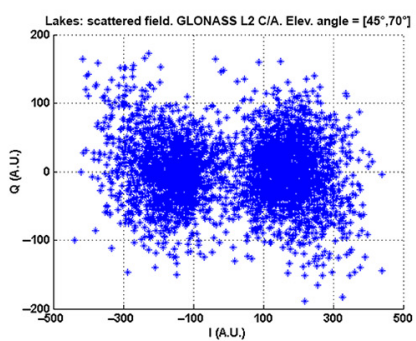

(f)

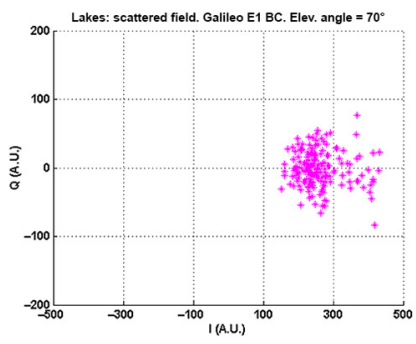

(h)
Fig. 3. Scattered complex field (peak of the complex waveform, $T_{c}$ from Table II, no incoherent averaging) for an elevation angle of $\theta_{e}=\left[45^{\circ}, 70^{\circ}\right]$ and a flight height $h \sim 27,000 \mathrm{~m}$. GPS L1 C/A (a) boreal forests and (b) lakes, GPS L2 C (c) boreal forests and (d) lakes, GLONASS L2 C/A (e) boreal forests and (f) lakes, and Galileo E1 BC boreal forests (g) and lakes (h).

\section{EXPERIMENTAL RESUlTS}

\section{A. Analysis of the Coherent-to-Incoherent Scattering Ratio}

The total scattered field of the GNSS signals during the float phase of the flight can be described as the vector sum of the different contributions (complex waveforms' peaks) in the complex plane. The ratio of the coherent and incoherent scattering components is analyzed using a data set of $\sim 2 \mathrm{~h}$, which corresponds to a flight height of $h \sim 27,000 \mathrm{~m}$ (Table I). The reflected complex waveforms were tracked using a delay locked loop (DLL), and a phase locked loop (PLL). The optimum parameters are provided in Table II, and were found empirically by changing PYCARO's configuration in real time during the experiment thanks to the E-Link.

Forests are characterized by random variations of the dielectric properties. The scattered field during the coherent integration time $T_{c}$ can be described as the sum of random vectors with phases $\phi_{m}$, and amplitudes $a_{m}$ (2). The total scattered fields during the float phase corresponding to GPS [Fig. 3(a), and (c)-forests and 3(b), and (d)-lakes], GLONASS [Fig. 3(e)-forests and 3(f)-lakes], and Galileo [Fig. 3(g)-forests and 3(h)-lakes] are represented in the complex plane for elevation angles in the range $\theta_{e}=\left[45^{\circ}, 70^{\circ}\right]$. In Fig. 3(a), (b), (e), and (f), there are two regions displaced by $\pm\left|\left\langle Y_{r, P e a k}\right\rangle\right|$ (mean of the amplitude distribution) from the center of the complex plane for both the GPS L1 C/A and GLONASS L2 C/A signals, because of the phase changes associated to the navigation bit. GPS L2 C [Fig. 3(c) and (d)] and Galileo E1 BC [Fig. 3(g) and (h)] are the so-called data-less channels or pilot channels. The tracking of the code is done coherently because no data bit is present. The complex plane representation is then centered in a region displaced $+\left|\left\langle Y_{r, P e a k}\right\rangle\right|$ from the center. These I/Q scatter plots show how the behavior changes depending on the scattering surface: from poorly coherent over boreal forests, to highly coherent over lakes. The relative weight of the coherentto-incoherent components is quantified by the following ratio [33, pp. 126]:

$$
B^{2}=\frac{\left|\left\langle Y_{r, \text { Peak }}\right\rangle\right|^{2}}{\sigma_{\text {Real }\left(Y_{r, \text { Peak }}\right)}^{2}+\sigma_{\operatorname{Im}\left(Y_{r, \text { Peak }}\right)}^{2}}
$$

where $\left|\left\langle Y_{r, \text { Peak }}\right\rangle\right|^{2}$ is the mean of the power distribution, and $\sigma_{\text {Real }\left(Y_{r, \text { Peak }}\right)}^{2}$ and $\sigma_{\operatorname{Im}\left(Y_{r, \text { Peak }}\right)}^{2}$ are the variances of the real and imaginary components of the complex cross-correlation waveforms peak after retracking. Note that $B$ tends to $\infty$ for a totally coherent field, and it is equal to 0 for a totally incoherent field. If the scatter plot was centered around $(0,0)$, the scattering would be completely incoherent. However, the scattered field is clearly displaced from the origin by a value equal to the mean of the amplitude distribution.

Over boreal forests, the ratio $B^{2}$ (Table I) shows the presence of a coherent component which is $B^{2} \sim 1.5$ for GPS and GLONASS signals for elevation angles in the range ${ }^{3} \theta_{e}=$ $\left[45^{\circ}, 70^{\circ}\right]$, and it is $\sim 2.1$ for Galileo signals for elevation angles in the range $\theta_{e}=\left[60^{\circ}, 70^{\circ}\right]$. This value is slightly different for the different codes because of the different scattering properties of the forested areas at the time of signal acquisition (different tracks and time periods), and slightly different elevation angles. On the other side, over lakes the ratio $B^{2}$ is much higher, up to 16.5 for Galileo signals, and in the range [3.9, 7.9] for GPS and GLONASS. Additionally, the standard deviation of the phase at the peak of the complex waveforms after retracking is in the range $\left[27^{\circ}, 35^{\circ}\right]$ over boreal forests, and $\left[5.7^{\circ}, 20.7^{\circ}\right]$ over lakes. This value (Table I) is lower at L2 as compared to the L1 measurements (up $\sim 3^{\circ}$ for GPS L1 C/A over forests and up $\sim 8^{\circ}$ for GPS L2 C over lakes). One reason is that the effective roughness is lower, as the signal wavelength is larger $\left(\lambda_{L 1}=19 \mathrm{~cm}\right.$ and $\left.\lambda_{L 2}=24 \mathrm{~cm}\right)$. The amount of Galileo signals collected along the flight were significant lower than the GPS and GLONASS ones, due to the lesser number of satellites, and to the fact that the CBOC modulation and the steeper

\footnotetext{
${ }^{3}$ It was selected because this is the range with higher antenna gain. Also note that there was no signal acquisition for elevation angles higher than $\sim 70^{\circ}$ because the high latitude of the experiment site.
} 


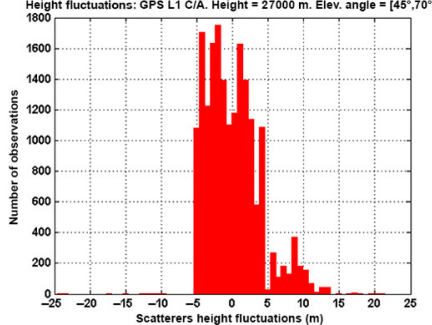

(a)

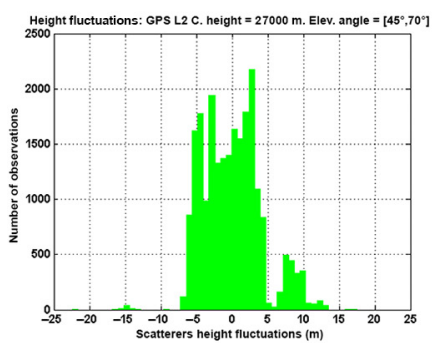

(c)

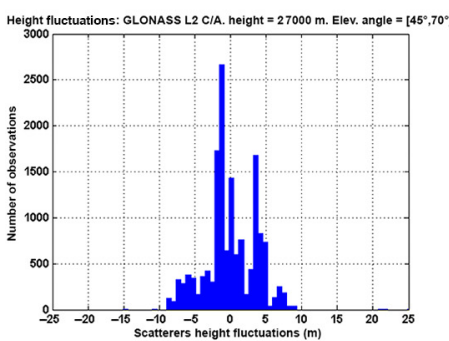

(e)

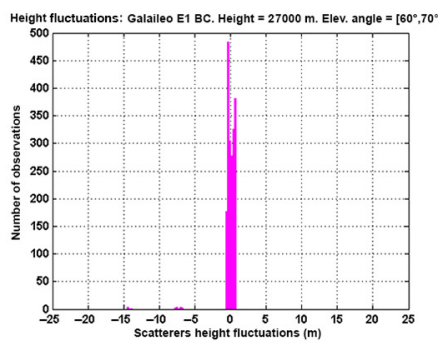

(g)

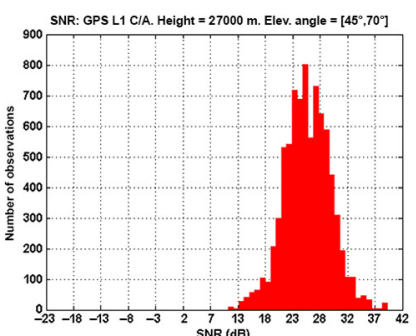

(b)

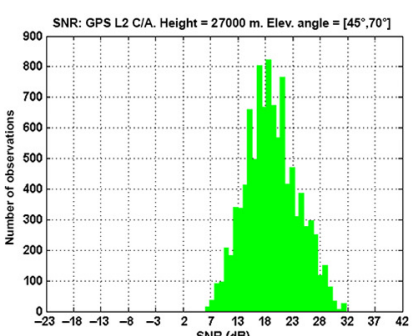

(d)

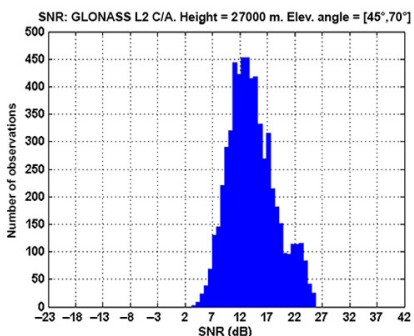

(f)

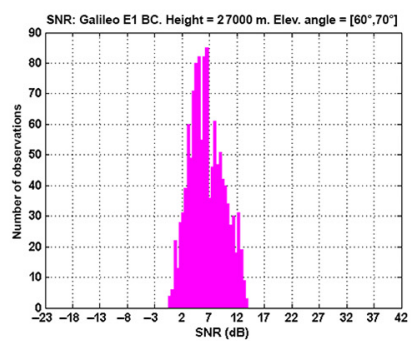

(h)
Fig. 4. Height fluctuations of the scatterers and post coherent-correlation SNR over boreal forests for an elevation angle $\theta_{e}=\left[45^{\circ}, 70^{\circ}\right]$ and a flight height $h \sim 27,000 \mathrm{~m}$. GPS L1 C/A boreal forests (a,b), GPS L2 C boreal forests (c,d), GLONASS L2 C/A boreal forests (e,f), and Galileo E1 BC boreal forests $(\mathrm{g}, \mathrm{h})$.

$A C F$ translate into a higher filtering of the coherent scattered signals and a lower signal-to-noise ratio (SNR).

\section{B. Scattering Properties Over Boreal Forests}

The coherent scattering over boreal forests (soil, trunks, branches, and leaves) is now studied using the signatures in the phase $\Psi_{n}$ of the peak of the complex waveforms before retracking $\left(Y_{r, \text { Peak }}\right)$. The information contained in the unwrapped phase is translated into height fluctuations of the scatterers using (4). The distributions of these height and post-coherentcorrelation SNR fluctuations over boreal forests are represented for the different signals: GPS L1 C/A [Fig. 4(a) and (b)], GPS L2 C [Fig. 4(c) and (d)], GLONASS L2 C/A [Fig. 4(e) and (f)], and Galileo [Fig. 4(g) and (h)]. The SNR decreases with increasing values of the receiver bandwidth (4 MHz GPS
TABLE III

SEMimajor Axis of THE First Chip Isodelay Ellipse, SEMIMAJOR AXIS OF THE First Fresnel ZONE AT DifFERENT ElEVATION ANGLES $\left(\theta_{e}=45^{\circ}\right.$ and $\left.\theta_{e}=70^{\circ}\right)$ AND AT A FLIGHT HEIGHT OF $h \sim 27,000 \mathrm{~m}$ FOR GPS, GLONASS, AND GALILEO SIGNALS

\begin{tabular}{ccccc}
\hline & $\begin{array}{c}\text { Semimajor } \\
\text { axis first } \\
\text { chip } \\
\text { ellipse (m) } \\
\theta_{e}=70^{\circ}\end{array}$ & $\begin{array}{c}\text { Semimajor } \\
\text { axis first } \\
\text { zone (m) } \\
\theta_{e}=70^{\circ}\end{array}$ & $\begin{array}{c}\text { Semimajor } \\
\text { axis first } \\
\text { chip } \\
\text { ellipse (m) } \\
\theta_{e}=45^{\circ}\end{array}$ & $\begin{array}{c}\text { Semimajor } \\
\text { axis first } \\
\text { zone (m) } \\
\theta_{e}=45^{\circ}\end{array}$ \\
\hline GPS L1 C/A & 4366 & 78 & 6689 & 120 \\
\hline GPS L2 C & 6175 & 88 & 9460 & 135 \\
\hline GPS L2 P(Y) & 1380 & 88 & 2115 & 135 \\
\hline GPS L1 P(Y) & 1380 & 78 & 2115 & 120 \\
\hline GLONASS L1 C/A & 6175 & 78 & 9460 & 120 \\
\hline GLONASS L2 C/A & 6175 & 88 & 9460 & 135 \\
\hline GLONASS L2 P & $\mathrm{x}$ & 88 & $\mathrm{x}$ & 135 \\
\hline Galileo E1 BC & 4366 & 78 & 6689 & 120 \\
\hline
\end{tabular}

L1 C/A, 6 MHz GPS L2 C, 19 MHz GLONASS L2 C/A, and $24 \mathrm{MHz}$ Galileo E1 BC). For GPS and GLONASS, the maximum value of the estimated SNR is $\sim 39 \mathrm{~dB}$ for GPS L1 C/A, $\sim 32 \mathrm{~dB}$ for GPS L2 C, and $\sim 26 \mathrm{~dB}$ for GLONASS $\mathrm{L} 2 \mathrm{C} / \mathrm{A}$, and the variation is in a range of $\sim[24,27] \mathrm{dB}$ which can be attributed to the different ground-tracks of the specular reflection points. The height fluctuations exhibit a multimodal behavior and are as high as $\pm 10 \mathrm{~m}$ for GPS and GLONASS. However, for the Galileo signals, due to the larger bandwidth and the lower SNR $(\mathrm{SNR}<14 \mathrm{~dB})$ only the strongest reflections are tracked, those coming from the soil, so height fluctuations are usually much smaller $(\sim 0.5 \mathrm{~m})$ except for a peak of $\sim-7 \mathrm{~m}$. These empirical results suggest that coherent scattering is taking place not only over the soil (higher SNR because the higher reflectivity, and lower height dispersion), but also over the trees which produces a multimodal behavior with clearly differentiated levels of SNR which may include multiple reflections involving canopy and soil as suggested in [34].

\section{Reflectivity Maps}

The cross-polar reflectivity $\Gamma_{r l}$ is estimated as the ratio of the reflected $\left(Y_{r, \text { Peak }}^{L H C P}\right)$ and direct $\left(Y_{d, \text { Peak }}^{R H C P}\right)$ power waveforms peaks, after proper compensation of the noise power floor and the antenna gains (nadir and zenith-looking) as a function of the elevation angle

$$
\Gamma_{r l}=\frac{\left\langle\left|Y_{r, \text { Peak }}^{\text {LHCP }}\right|^{2}\right\rangle}{\left\langle\left.{ }^{\mid} Y_{d, \text { Peak }}^{R H C P}\right|^{2}\right\rangle} .
$$

In (6), superscripts $R H C P$ and $L H C P$ denote the incident polarization (RHCP), and the scattered polarization (LHCP), respectively. The correlation parameters in the computation of the waveforms are important for the evaluation 


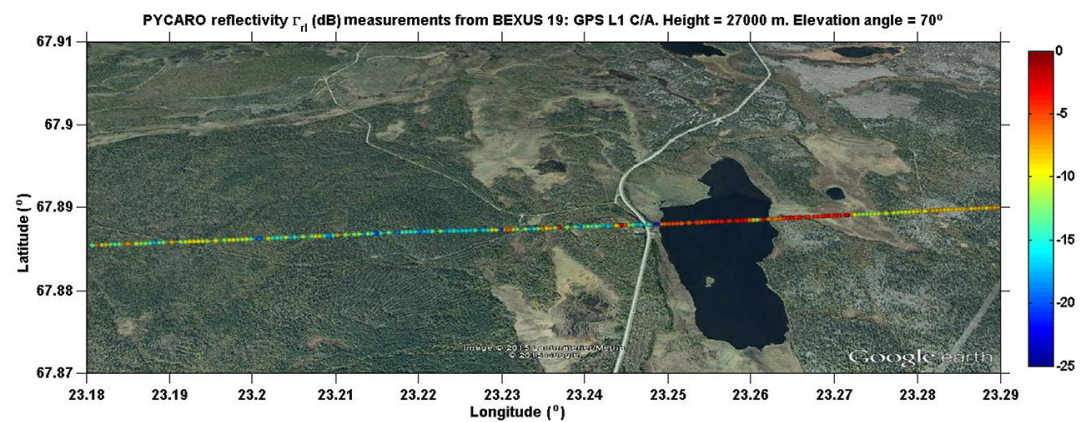

(a)

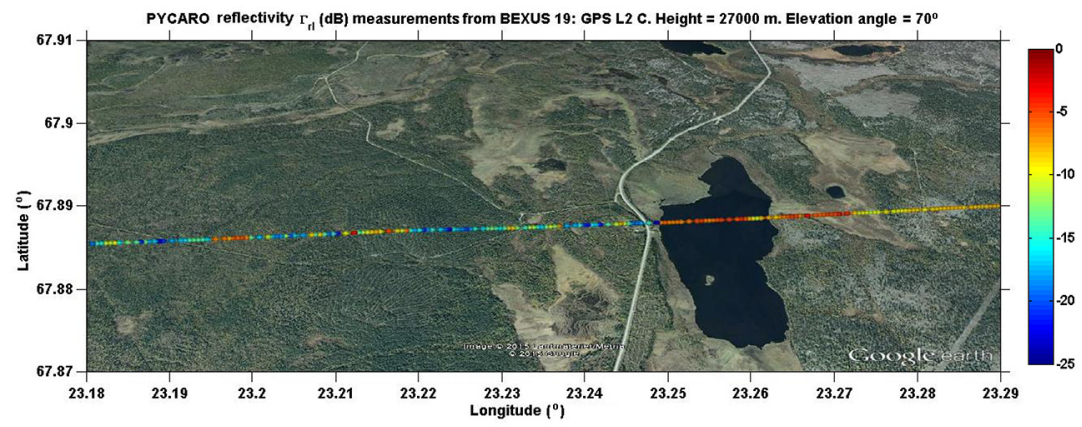

(b)

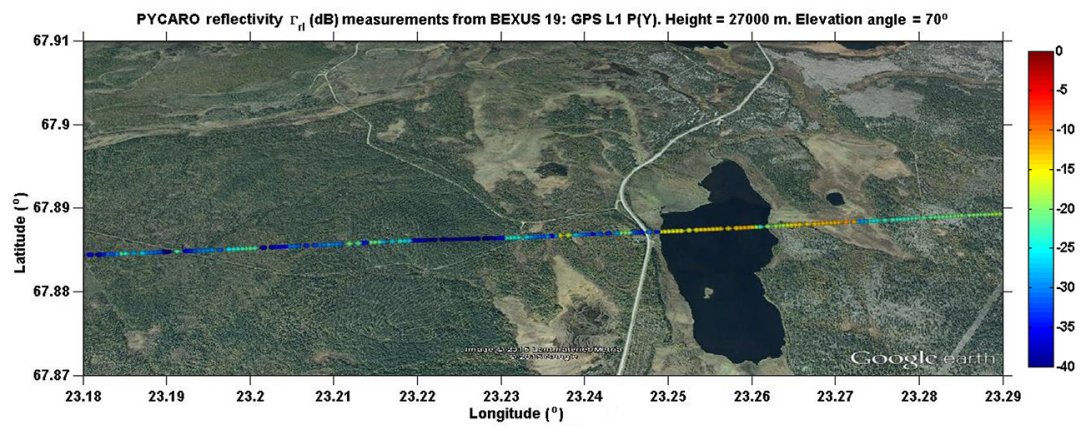

(c)

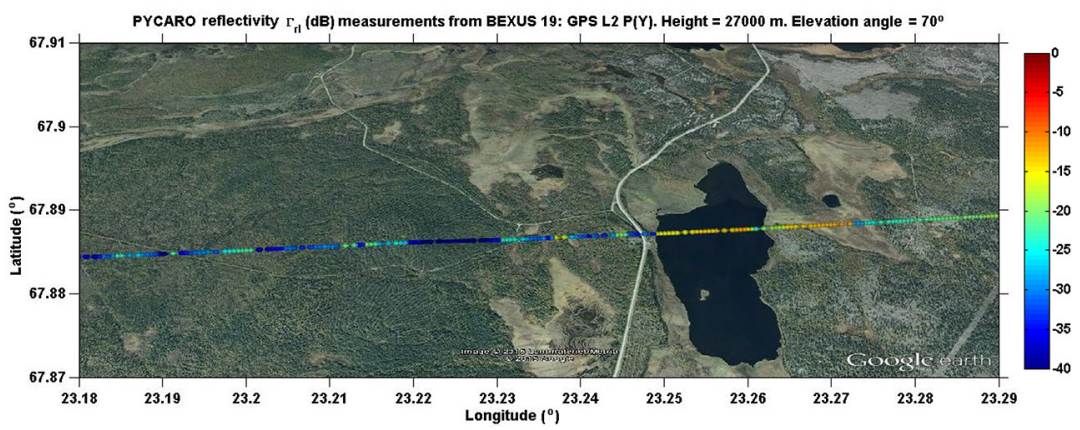

(d)

Fig. 5. Cross-polar reflectivity maps (LHCP-reflected) geolocated over the nominal specular points over boreals forests and lakes for GPS signals. (a) L1 C/A. (b) L2 C. (c) L1 P(Y). (d) L2 P(Y).

of the results. The DLL and the PLL coherent integration times $\left(T_{c}^{D L L}\right.$ and $\left.T_{c}^{P L L}\right)$, the number of incoherent averaging samples $\left(N_{i n c}^{D L L}\right)$, and the DLL and PLL bandwidths $\left(B^{D L L}\right.$ and $\left.B^{P L L}\right)$ are included in Table II. The PLL coherent integration time was set to be $10 \mathrm{~ms}$ for all the codes, ${ }^{4}$ and

${ }^{4}$ GLONASS L2 P [30] and Galileo E1 BC [32] codes where limited by their navigation data bit period $(4 \mathrm{~ms})$. the $B^{P L L}=15 \mathrm{~Hz}$ to tolerate abrupt phase changes due to the scattering process over boreal forests. The DLL coherent integration time $\left(T_{c}^{D L L}\right)$ was set to be equal to the navigation data bit period for each code [29]-[32] because during the experiment preparation activities, it was determined that the SNR increased as a function of the coherent integration time up to $13 \mathrm{~dB}$ for $T_{c}^{D L L}=20 \mathrm{~ms}$. The DLL optimum bandwidth was set empirically during the experiment to be $B^{D L L}=0.01 \mathrm{~Hz}$ 


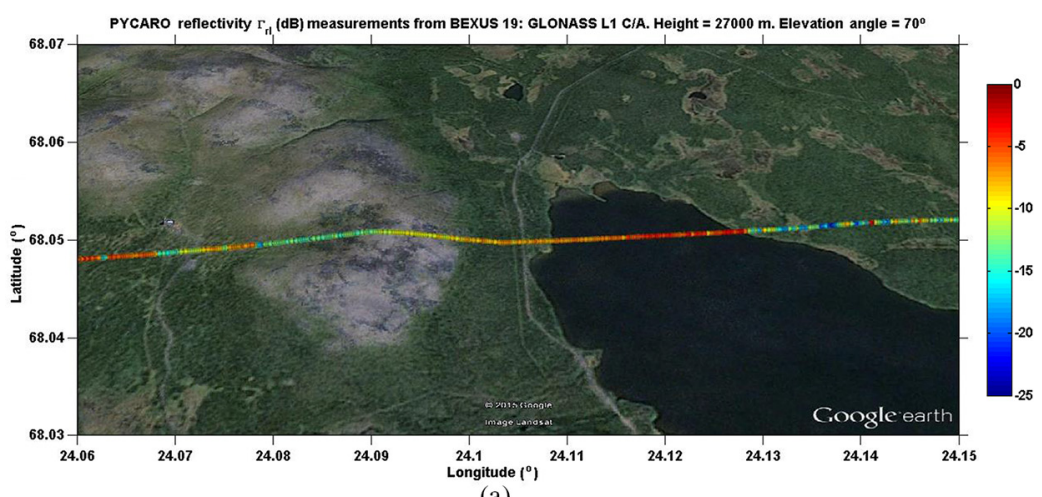

(a)

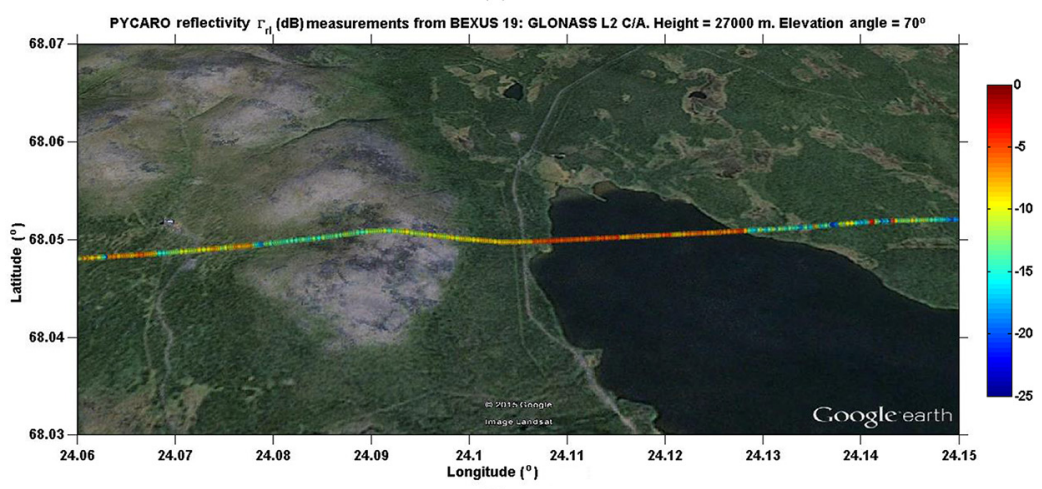

(b)

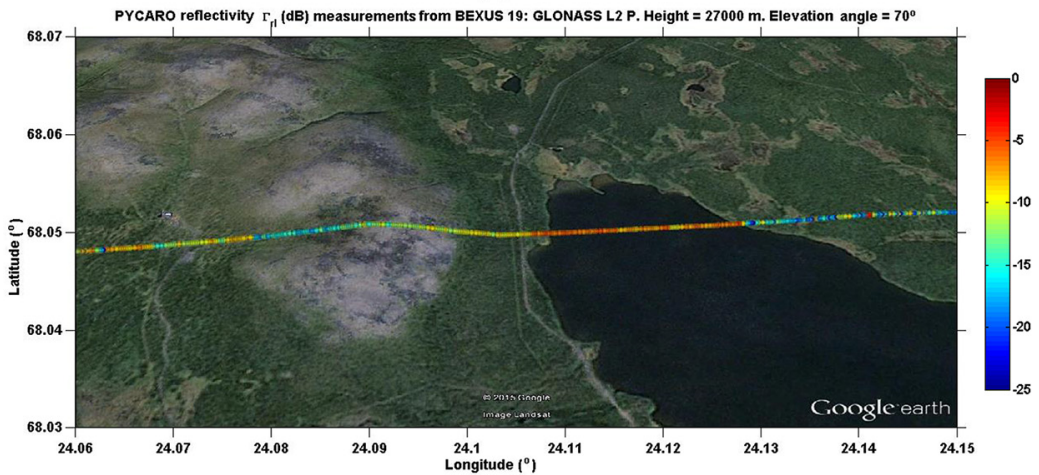

(c)

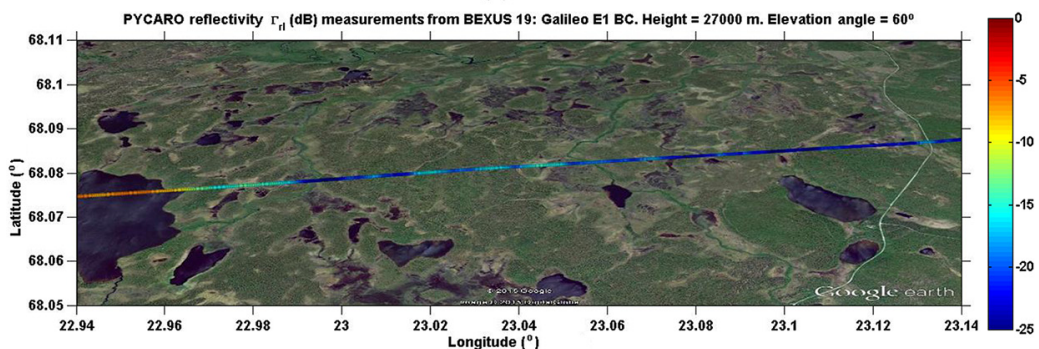

(d)

Fig. 6. Cross-polar reflectivity maps (LHCP-reflected) geolocated over the nominal specular points over boreals forests and lakes for GLONASS signals. (a) L1 C/A. (b) L2 C/A. (c) L2 P. (d) Galileo E1 BC signals.

to stabilize the frequency after getting locked. After the estimation of the reflectivity values, the specular points were geolocalizated over Google Maps for the sake of a simpler data interpretation. The orbit parameters of the GNSS satellites were obtained from the ephemerides as provided by an on-board positioning receiver, while the PYCARO trajectory was determined using the on-board receiver. Before the evaluation of the results, some theoretical considerations about the reflectivity estimation algorithms are commented. The reflectivity values as estimated using (6) introduce a dependency with the platform height through the $W A F$ in $Y_{r, P e a k}$ (2), due to the different sizes of the scattering area, which is translated into different power levels of the reflected signals [35]. For the flight conditions ( $h \sim 27,000 \mathrm{~m}$ and scattering over land surfaces), the Earth region contributing to the incoherent component is inside the first chip isodelay ellipse which is a function of the 
$A C F$ of the different GNSS codes. On the other side, the area contributing to the coherent component is limited by the first Fresnel zone, which actually depends on the signal wavelength. These values are summarized in Table III.

Figs. 5 and 6 show the reflectivity values using GPS, GLONASS, and Galileo signals. cGNSS-R was used for computation of the waveforms using GPS L1 C/A [Fig. 5(a)], GPS L2 C [Fig. 5(b)], GLONASS L1 C/A [Fig. 6(a)], GLONASS L2 C/A [Fig. 6(b)], GLONASS L2 P [Fig. 6(c)], and Galileo E1 BC [Fig. 6(d)], while rGNSS-R for GPS L1 P(Y) and L2 $\mathrm{P}(\mathrm{Y})$ [Fig. 5(c) and (d)]. The reflectivity values are as high as $-2 \mathrm{~dB}$ over lakes. On the other side, they show large fluctuations from -3 to $-25 \mathrm{~dB}$, over boreal forests. Note that over flat freshwater surfaces the reflectivity values $(\sim-2 \mathrm{~dB})$ agree with the expected Fresnel reflectivity $(\sim 0.64)$, while, over forests reflectivity values are much lower. When using cGNSS-R, the reflectivity shows a similar behavior for the different codes of each GNSS system. The coherent component, the one actually tracked by PYCARO, is coming from an area equal to the first Fresnel zone. Therefore, although the $W A F$ spreads the signal over areas of different size, $\Gamma_{r l}$ follows the same trend independently of the code and the signal wavelength. Finally, the rGNSS-R is evaluated successfully for first time over forested areas, despite the high dispersion of the signal induced by the scattering media. Reflectivity values are $\sim 10 \mathrm{~dB}$ below those obtained by cGNSS-R because of the squaring losses of the $\mathrm{P}(\mathrm{Y})$ code correlation technique implemented in PYCARO, which exhibits a nonlinear dependence with the SNR of the incoming signal [7]: the lower the SNR, the larger the squaring losses [36].

\section{SUMmARY AND CONCLUSION}

This work has presented the first dual-frequency GNSS$\mathrm{R}$ observations using GPS, GLONASS, and Galileo E1 BC signals, collected from a stratospheric balloon experiment performed North of Sweden using the PYCARO reflectometer. LHCP reflected signals were collected with an antenna array of $\sim 13 \mathrm{~dB}$ gain at $\mathrm{L} 1$ and $\sim 12 \mathrm{~dB}$ gain at L2. Results show the feasibility of tracking the coherent component of the scattering over boreal forests and lakes even from high altitude platforms. The coherent-to-incoherent ratio of the scattered signals for high elevation angles $\theta_{e}=\left[45^{\circ}, 70^{\circ}\right]$ is found to be $\sim 1.5$ over boreal forests, while over lakes, it is in the range $[3.9,7.9]$ for GPS and GLONASS, and it is high up to 16.5 for Galileo signals. The height distribution of the scatterers has been derived from the fluctuations of the phase of the complex waveforms peak, which range from $\pm 10 \mathrm{~m}$ to the submeter level. Reflectivity values are highly variable from -3 to $-25 \mathrm{~dB}$, as derived using cGNSS-R. Reflectivity maps derived from the different codes of each GNSS system are highly similar despite the different power spreading over the scattering media induced by the different ACFs. Actually, the coherent component provides the highest power contribution to the peak of the complex waveforms. As a consequence, the fluctuations of the signal power depend only on an area equal to the first Fresnel zone for a rough scattering media. Additionally, the rGNSS-R technique has been successfully tested. PYCARO was able to reconstruct the GPS P(Y) code despite the large dispersion of the signal after the scattering over the boreal forests. As a main conclusion, the analysis of the GNSS-R complex waveforms shows a coherent multimodal contribution after the signal scattering over forested regions. The performance of GNSS-R in terms of spatiotemporal sampling will benefit when future GNSS constellations will be fully operational. Geophysical parameters retrieval over high latitude targets (in particular, biomass monitoring) will take advantage of the highest orbital inclination of the navigation system.

\section{ACKNOWLEDGMENT}

The authors would like to thank Pons and Khoe from the administration of the Department of Signal Theory and Communications (TSC), and for the collaboration during the project to several undergraduate students (A. Amèzaga, R. Olivé, D. Vidal, and J. F. Munoz) of the Universitat Politècnica de Catalunya-BarcelonaTech (UPC). The authors also thank to the REXUS/BEXUS team for their collaboration, help and advice during the campaign and special thanks to Dra. Natacha Callens (ESA) and A. Kinnaird (SSC) for their help during the flight campaign, and to S. Vey (ESA) for his advice during the thermal analysis.

\section{REFERENCES}

[1] M. Martín-Neira, "A passive reflectometry and interferometry system (PARIS): Application to ocean altimetry," ESA J., vol. 17, pp. 331-355, 1993.

[2] J. L. Garrison, S. J. Katzberg, and M. I. Hill, "Effect of sea roughness on bistatically scattered range coded signals from the global positioning system," Geophys. Res. Lett., vol. 25, no. 13, pp. 2257-2260, 1998.

[3] F. Fabra, "GNSS-R as a source of opportunity for remote sensing of the cryosphere," Ph.D. Dissertation, Universitat Politècnica de Catalunya, Barcelona, Spain, 2014, [Online]. Available: www.tdx.cat/bitstream/ 10803/117605/1/TFFC1de3.pdf, accessed on May 10, 2015.

[4] N. Rodriguez-Alvarez, "Contributions to earth observation using GNSSR opportunity signals," Ph.D. Dissertation, Universitat Politècnica de Catalunya, Barcelona, Spain, 2011 [Online]. Available: http://www.tdx. cat/handle/10803/53636, accessed on May 04, 2015.

[5] J. L. Garrison, A. Komjathy, V. U. Zavorotny, and S. J. Katzberg, "Wind speed measurement using forward scattered GPS signals," IEEE Trans. Geosci. Remote Sens., vol. 40, no. 1, pp. 50-65, Jan. 2002.

[6] E. Cardellach et al., "Consolidating the precision of interferometric GNSS-R ocean altimetry using airborne experimental data," IEEE Trans. Geosci. Remote Sens., vol. 52, no. 8, pp. 4992-5004, Aug. 2014.

[7] H. Carreno-Luengo, A. Camps, I. Ramos-Pérez, and A. Rius, "Experimental evaluation of GNSS-Reflectometry altimetric precision using the $\mathrm{P}(\mathrm{Y})$ and C/A signals," IEEE J. Sel. Topics Appl. Earth Observ. Remote Sens., vol. 7, no. 5, pp. 1493-1500, May 2014.

[8] J. Dampf, T. Pany, N. Falk, B. Riedl, and J. O. Winkel, "Galileo altimetry using AltBOC and RTK techniques," Inside GNSS, 2013, pp. 54-63 [Online]. Available: http://www.insidegnss.com/auto/janfeb13-WP.pdf, accessed on Apr. 12, 2015.

[9] T. Hobiger, R. Haas, and J. S. Löfgren, "GLONASS-R: GNSS reflectometry with a frequency division multiple access-based satellite navigation system," Radio Sci., vol. 49, no, 4, pp. 271-282, 2014.

[10] M. Arcioni et al., "ESA's biomass mission candidate system and payload overview," in Proc. IEEE Int. Geosci. Remote Sens. Symp. (IGARSS'12), Munich, Germany, Jul. 2012, pp. 5530-5533.

[11] P. Ferrazzoli, L. Guerriero, N. Pierdicca, and R. Rahmoune, "Forest biomass monitoring with GNSS-R: Theoretical simulations," Adv. Space Res., vol. 47, no. 10, pp. 1823-1832, 2011.

[12] M. Unwin et al., "Sea state determination with GNSS reflectometry on TechDemoSat-1," in Proc. ESA Small Satell. Syst. Serv. Symp., Mallorca, Spain, May 2014, pp. 1-15. 
[13] R. Rose, W. Wells, D. Rose, C. Ruf, A. Ridley, and K. Nave, "Nanosat technology and managed risk: An update of the CyGNSS microsatellite constellation mission development," in Proc. 28th AIAA/USU Conf. Small Satell., Logan, UT, USA, Aug. 2014, pp. 1-12.

[14] J. Wickert et al., "GEROS-ISS-GNSS reflectometry, radio occultation and scatterometry on-board the International Space Station," in Proc. 4th Int. Colloq. Sci. Fundam. Aspects Galileo Program., Prague, Czech Republic, Dec. 2013, pp. 1-3.

[15] M. Martín-Neira, S. D’Addio, C. Buck, N. Floury, and R. Prieto-Cerdeira, "The PARIS ocean altimeter in-orbit demonstrator," IEEE Trans. Geosci. Remote Sens., vol. 49, no. 6, pp. 2209-2237, Jun.2011.

[16] H. Carreno-Luengo et al., "The ${ }^{3}$ Cat-2 project: GNSS-R in-orbit demonstrator for earth observation," in Proc. ESA Small Satell. Syst. Serv. Symp., Mallorca, Spain, May 2014, pp. 1-10.

[17] A. Egido et al., "Airborne GNSS-R soil moisture and above ground biomass observations," IEEE J. Sel. Topics Appl. Earth Observ. Remote Sens., vol. 7, no. 5, pp. 1522-1532, May 2014.

[18] A. K. Fung and H. J. Eom, "Coherent scattering of a spherical wave from an irregular surface," IEEE Trans. Geosci. Remote Sens., vol. 31, no. 1, pp. 68-72, Jan. 1983.

[19] N. Pierdicca, L. Guerriero, M. Brogioni, and A. Egido, "On the coherent and non coherent components of bare and vegetated terrain bistatic scattering: Modelling the GNSS-R signal over land," in Proc. IEEE Int. Geosci. Remote Sens. Symp. (IGARSS'12), Munich, Germany, Jul. 2012, pp. 3407-3410.

[20] X. R. Wu and S. G. Jin, "GPS-Reflectometry: Forest canopies polarization scattering properties and modelling," Adv. Space Res., vol. 54, pp. 863870, 2014

[21] E. Cardellach, G. Ruffini, D. Pino, A. Rius, A. Komjathy, and J. L. Garrison, "Mediterranean balloon experiment: Ocean wind speed sensing from the stratosphere, using GPS reflections," Remote Sens. Environ., vol. 88, pp. 351-362. 2003.

[22] A. T. Caicoya, F. Kugler, I. Hajnsek, and K. Papathanassiou, "Boreal forest biomass classification with TANDEM-X," in Proc. IEEE Int. Geosci. Remote Sens. Symp. (IGARSS'12), Munich, Germany, Jul. 2012, pp. 3439-3442.

[23] NASA/JPL-Caltech, Global Map of Forest Height Produced From NASA's ICESAT/GLAS, MODIS and TRMM Sensors [Online]. Available: http://www.nasa.gov/topics/earth/features/earth20120217map.html, accessed on Aug. 5, 2015.

[24] A. Kinnaird. (2014). BEXUS User Manual, ID: BX_REF_BX_user manual v6-10_05Feb14 [Online]. Available: http://www.rexusbexus. net/index.php?option=com_content $\&$ view $=$ article $\&$ id $=51 \&$ Itemid $=63$, accessed on Jun. 1, 2015.

[25] M. I. Skolnik, Radar Handbook. 2nd ed. New York, NY, USA: McGraw Hill, 1990.

[26] V. U. Zavarotny and A. G. Voronovich, "Scattering of GPS signals from the ocean with wind remote sensing application," IEEE Trans. Geosci. Remote Sens., vol. 38, no. 2, pp. 951-964, Mar. 2000.

[27] D. Pascual, H. Park, A. Camps, A. Alonso-Arroyo, and R. Onrubia, "Simulation and analysis of GNSS-R composite waveforms using GPS and Galileo signals," IEEE J. Sel. Topics Appl. Earth Observ. Remote Sens., vol. 7, no. 5, pp. 1461-1468, May 2014.

[28] H. Carreno-Luengo, H. Park, A. Camps, F. Fabra, and A. Rius, "GNSS-R derived centimetric sea topography: An airborne experiment demonstration," IEEE J. Sel. Topics Appl. Earth Observ. Remote Sens., vol. 6, no. 3, pp. 1468-1478, Jun. 2013.

[29] S. U. Qaisar and A. G. Dempster, "Cross-correlation performance comparison of L1 \& L2 C GPS codes for weak signal acquisition," in Proc. Int. Symp. GPS/GNSS, Yokohama, Japan, Nov. 2008, pp. 1-9.

[30] F. Boon, J. M. Sleewaegen, A. Simsky, and W. De Wilde, "GPS+GLONASS RTK: Making the choice between civilian and military L2 GLONASS," in Proc. 21st Int. Tech. Meeting Satell. Div. Inst. Navig., Savannah, GA, USA, Sep. 2008, pp. 2860-2867.

[31] Russian Institute of Space Device Engineering (2008). GLONASS Interface Control Document [Online]. Available: http://www.spacecorp. $\mathrm{ru} / \mathrm{upload} / \mathrm{iblock} / 1 \mathrm{c} 4 / \mathrm{cgs}$-aaixymyt $\% 205.1 \% 20 \mathrm{ENG} \% 20 \mathrm{v} \% 2020$ 14.02.18w.pdf, accessed on Mar. 9, 2015.

[32] K. Borre. (2009). "The E1 Galileo signal," Aalborg Univ., Denmark [Online]. Available: http://waas.stanford.edu/papers/Borre/galileo_sig. pdf, accessed on Mar. 9, 2015.

[33] P. Beckmann and A. Spizzichino, The Scattering of Electromagnetic Waves From Rough Surfaces. Norwood, MA, USA: Artech House, 1963.
[34] H. Carreno-Luengo, A. Camps, J. Querol, G. Forte, R. Onrubia, and R. Díez, "A stratospheric balloon experiment: The ${ }^{3}$ Cat-2 project in DLR/SNSB BEXUS," in Proc. IEEE Int. Geosci. Remote Sens. Symp. (IGARSS'14), Quebec, Canada, Jul. 2014, pp. 3626-3629.

[35] S. D'Addio and M. Martín-Neira, "Comparison of processing techniques for remote sensing of earth-exploiting reflected radio-navigation signals," IEEE Electron. Lett., vol. 49, no. 4, pp. 292-293, Feb. 2013.

[36] T. K. Woo, "Optimum semi-codeless carrier phase tracking of L2," in Proc. 12th Int. Tech. Meeting Satell. Div. Inst. Nav., Nashville, TN, USA, Sep. 1999, pp. 82-89.

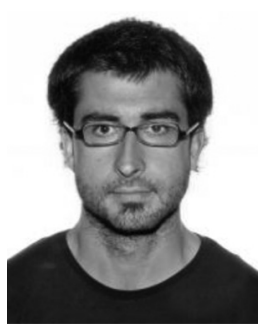

Hugo Carreno-Luengo (S'12-M'14) received the M.St. degree in aeronautical engineering (specialization in spacecrafts) from the E.T.S.I.Aeronáuticos, Universidad Politécnica de Madrid (UPM), Madrid, Spain, in 2010. Currently, he is pursuing the $\mathrm{Ph} . \mathrm{D}$. degree in Remote Sensing from Universitat Politècnica de Catalunya (UPC), Barcelona, Spain,

In 2011, he joined the Remote Sensing Laboratory, UPC, where he is provided with a fellowship of the Institute for Space Studies of Catalonia (IEEC). From 2012 to 2015, he was the Team Leader of the TORMES and TORMES 2.0 teams in the frame of the European Space Agency (ESA) Balloon EXperiments for University Students (BEXUS) 17 and 19 stratospheric flight campaigns. His research interests include the use of global navigation satellite systems reflectometry (GNSS-R) techniques to perform earth remote sensing from nanosatellites.

Mr. Carreno-Luengo was Session Chair at the IEEE IGARSS 2015. Currently, he is with the UPC team in the E-GEM-European GNSS-R Environmental Monitoring PF7 project.

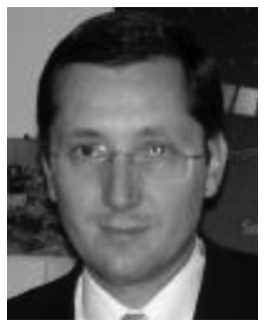

Adriano Camps (S'91-A'97-M'00-SM'03-F'11) was born in Barcelona, Spain, in 1969. He received the degree in telecommunications engineering and the Ph.D. degree in telecommunications engineering from the Universitat Politècnica de Catalunya (UPC), Barcelona, Spain, in 1992 and 1996, respectively.

From 1991 to 1992, he was with the ENS des Télécommunications de Bretagne, France, with an Erasmus Fellowship. Since 1993, he has been with the Electromagnetics and Photonics Engineering Group, Department of Signal Theory and Communications, UPC, where he was the first Assistant Professor, Associate Professor in 1997, and has been a Full Professor since 2007. Since 1993, he has been deeply involved in the European Space Agency SMOS Earth Explorer Mission, from the instrument and algorithmic points of view. He has authored nearly 100 papers in peer-reviewed journals, and more than 200 international conference presentations. His research interests include microwave remote sensing, with special emphasis in microwave radiometry by aperture synthesis techniques and remote sensing using signals of opportunity (GNSS-R).

Dr. Camps was Chair of u Cal 2001, Technical Program Committee CoChair of IGARSS 2007, and Co-Chair of GNSS-R '10. Currently, he is an Associate Editor for Radio Science and the IEEE TRANSACTIONS ON GEOSCIENCE AND REMOTE SENSING, and President-Founder of the IEEE Geoscience and Remote Sensing Society Chapter at Spain. In 1993, he was the recipient of the Second National Award of University Studies; in 1997, and was also a recipient of the INDRA award of the Spanish Association of Telecommunication Engineers to the best Ph.D. in remote sensing; in 1999, he was a recipient of the Extraordinary Ph.D. Award at the Universitat Politècnica de Catalunya; in 2002, the Research Distinction of the Generalitat de Catalunya for contributions to microwave passive remote sensing; and in 2004, he was a recipient of a European Young Investigator Award, and in 2009, the ICREA Academia Award. Moreover, as a Member of the Microwave Radiometry Group, UPC, he was a recipient of the 1st Duran Farell, the Ciutat de Barcelona Awards for Technology Transfer, in 2000, 2001, and 2004, respectively, and the "Salvà i Campillo" Award of the Professional Association of Telecommunication Engineers of Catalonia for the most innovative research project for MIRAS/SMOS-related activities, and in 2010, the 7th Duran Farell Award for Technological Research for the work on GNSS-R instrumentation and applications. 